\title{
Four-level minimally invasive lateral interbody fusion for treatment of degenerative scoliosis
}

\author{
Beejal Y. Amin, M.D., ${ }^{1}$ Praveen V. Mummaneni, M.D., 2 Tarik Ibrahim, M.D., 1 \\ Alex Zouzias, M.D., ${ }^{3}$ AND Juan Uribe, M.D. ${ }^{3}$
}

${ }^{1}$ Department of Neurological Surgery, Loyola University Medical Center, Chicago, Illinois; ${ }^{2}$ Department of Neurological Surgery, University of California, San Francisco, California; and ${ }^{3}$ Department of Neurological Surgery, University of South Florida, Tampa, Florida

\begin{abstract}
The benefits of anterior interbody arthrodesis in deformity surgery are well known and include load sharing and increased fusion rates. A minimally invasive lateral transpsoas approach to the anterior lumbar spine is a promising alternative to traditional interbody techniques for the treatment of adult degenerative scoliosis. The reported advantages of the minimally invasive lateral transpsoas approach include reduced blood loss and shorter length of stay. However, there are several approach-related complications associated with this technique including injury to the nerves within the abdominal wall leading to abdominal wall paresis, bowel injury, and injury to the lumbar plexus.

In this video, we demonstrate the key steps of the minimally invasive lateral retroperitoneal transpsoas technique for interbody fusion in the treatment of adult degenerative scoliosis.

The video demonstrates patient positioning, surgical opening, passage through the anatomical safe zone, use of multidirectional EMG to navigate away from the lumbar plexus, placement of the expandable retractor, discectomy, endplate preparation, graft insertion, and wound closure. Special emphasis is placed on the approach. We highlight the relevant nerves passing through the abdominal wall with the aid of a microscope.

The video can be found here: http://youtu.be/XU1OujNF8F8.
\end{abstract}

(http://thejns.org/doi/abs/10.3171/2013.V2.FOCUS13198)

\section{Disclosure}

Dr. Mummaneni has received honoraria from DePuy and Globus. He receives a royalty from DePuy, Thieme Publishers, and Quality Medical Publishers. Dr. Uribe is a consultant for Nuvasive and Orthofix. He receives a grant from Nuvasive. Drs. Amin, Ibrahim, and Zouzias have no financial disclosures.

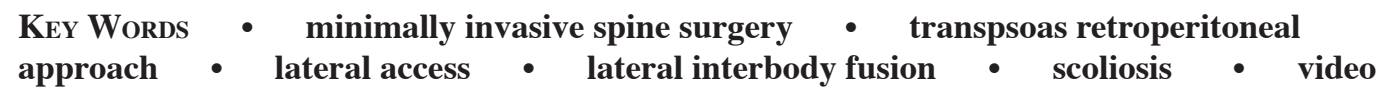

Manuscript submitted April 29, 2013

Accepted May 29, 2013.

Please include this information when citing this paper: DOI: 10.3171/2013.V2.FOCUS13198.

Address correspondence to: Beejal Y. Amin, M.D., Department of Neurological Surgery, Loyola University Medical Center, 2160 S. First Avenue, Bldg 105, Suite 1900, Maywood, IL 60153. email: bamin@lumc.edu. 